\title{
Walnut dehydrators vary in performance
}

\author{
Joseph A.Grant J James F. Thompson
}

\section{Samples from 11 walnut dehydra- tors in San Joaquin County showed substantial overdrying. Using grain moisture meters helps, but more accurate, faster methods are needed to test moisture of nuts throughout the bin.}

Since heated-air drying of walnuts began in the 1930s, many innovative steps have been taken to improve dehydrator performance and efficiency, including better ways of monitoring nut moisture content during drying. Dehydrators normally try to achieve a final average nut moisture content of around $8 \%$. This is considered the optimum moisture content for postharvest handling and stability.

Drying walnuts beyond $8 \%$ moisture wastes gas and electricity, results in lost tonnage, reduces dehydrator capacity, and may increase breakage of nuts during handling. Each $1 \%$ reduction in moisture below $8 \%$ results in the loss of approximately 20 pounds of nuts per ton dried. A dehydrator operator who dries 500 tons per year to an average $7 \%$ final moisture content, for example, needlessly removes 5 tons of moisture annually. This represents a direct loss in revenue for both the grower and the dehydrator. Proper drying to $8 \%$ moisture increases the amount the dehydrator can process within a specific period, allowing for smaller physical plant capacity and more timely harvesting.

\section{Dehydrator observations}

During the 1988 walnut harvest season, we studied the performance of selected walnut dehydrators in San Joaquin County. The objective was to assess the extent to which overdrying or underdrying was occurring among those dehydrators. Fixedbin, pot-hole, and trailer dryers were included among the 11 dehydrators who participated in the study (table 1).

Throughout the 5-week harvest season, we visited these dryers one to three times a week. At each visit, several pairs of 30-nut samples were collected at random from the conveyors loading "wet" nuts into bins for drying. We weighed these samples to determine initial moisture content, enclosed them in loose mesh bags, and placed them. in bins or trailers in pairs, one sample near the bottom and one near the top, as bins were being filled. Dehydrator operators were asked to remove the samples from the dryers as soon as drying was judged to be finished and to place each sample in a plastic bag to prevent further changes in moisture.

Within 1 or 2 days, we retrieved the dehydrated samples from each cooperator, and determined their final moisture content by weighing nuts before and after air-ovendrying for 48 hours at $200^{\circ} \mathrm{F}$. During the study, 81 tests were conducted at the 11 dryers. Varieties sampled included Payne, Hartley, Eureka, Vina, Serr, Pedro, Mayette, Franquette, and Nugget.

We estimated the final average moisture content of nuts in a bin by averaging the final moisture content of samples placed on the top and bottom of that bin. When evaluated in this way, two-thirds of bins sampled had average moisture contents below the $8 \%$ optimum level, and $41 \%$ yielded samples with average moisture content less than $7 \%$ (fig. 1). In addition, a surprisingly large number of samples were significantly underdried; $20 \%$ of bins sampled had average moisture contents above $9 \%$.

Individual cooperating dehydrators varied in their ability to dry accurately to $8 \%$ moisture (fig. 2). Final moisture in samples from dehydrators $S$ and $M$ bracketed $8 \%$ quite well. Cooperators $\mathrm{O}, \mathrm{A}$, and $\mathrm{G}$, on the other hand, showed a marked tendency toward underdrying, while $T$ and $E$ tended to overdry. Our samples suggest that dehydrators U, R, I, and J consistently overdried loads of nuts.

Cooperators who tended to underdry may have done so intentionally to increase

\begin{tabular}{lcc}
$\begin{array}{l}\text { TABLE 1. Average difference in moisture content } \\
\text { between samples placed on top and bottom of } \\
\text { dryer bins among participating dehydrators }\end{array}$ \\
\hline Cooperator, & $\begin{array}{c}\text { No. of } \\
\text { samples }\end{array}$ & $\begin{array}{c}\text { Top-bottom } \\
\text { difference in } \\
\text { moisture }\end{array}$ \\
\hline dryer type & & $\%$ \\
U, fixed bin & 4 & 0.7 \\
O, fixed bin & 7 & 4.3 \\
A, fixed bin & 5 & 5.6 \\
S, pot-hole & 12 & 3.1 \\
T, pot-hole & 13 & 1.9 \\
R, pot-hole & 10 & 3.1 \\
E, fixed bin & 7 & 1.0 \\
I, trailer & 4 & 0.9 \\
M, fixed bin & 9 & 3.7 \\
J, trailer & 3 & 2.5 \\
G, fixed bin & 5 & 3.3 \\
\hline
\end{tabular}

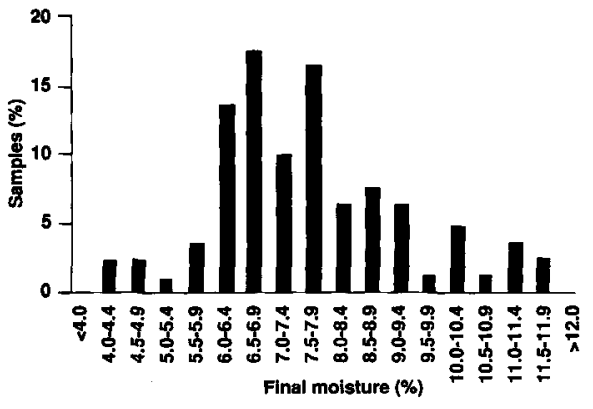

Fig. 1. Frequency distribution of average final bin moisture contents from all samples. - *o

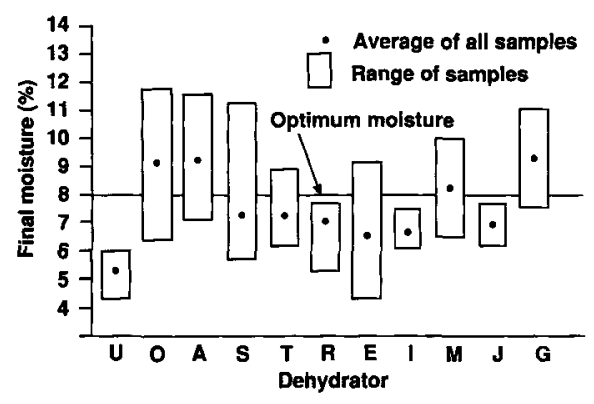

Fig. 2. Cooperating dehydrators varied widely in their ability to dry accurately to the optimum $8 \%$ moisture.

weight. Since underdried nuts are more susceptible to mold and other postharvest losses, most walnut handlers will not accept loads of nuts above $8 \%$ average moisture content. These dehydrators thus risk having underdried loads rejected by their handlers and returned for additional drying.

Because the heated air used to dehydrate nuts enters through the bottom of bins and exits from the top, the top nuts dry more slowly than those at the bottom or middle of the bins. This can lead to large differences in final moisture content of nuts from the bottom and top. Nuts are usually selected from the top to monitor moisture content during drying, because it is difficult to sample those from the bottom or middle of the bins. This practice can lead to substantial overdrying of bottom and middle nuts if drying is allowed to proceed until top nuts reach the optimum $8 \%$ moisture.

Project cooperators varied widely in the average difference in final moisture content between top and bottom samples (table 1). Several factors contribute to top-to-bottom 
